Illinois State University

ISU ReD: Research and eData

Theses and Dissertations

4-10-2014

\title{
Seeking a Better Understanding of Cyber Infidelity: applying Sternberg's Triangular Theory of Love to an atheoretical field
}

Lauren Elizabeth Hardy

Illinois State University, lehardy21@yahoo.com

Follow this and additional works at: https://ir.library.illinoisstate.edu/etd

Part of the Family, Life Course, and Society Commons

\section{Recommended Citation}

Hardy, Lauren Elizabeth, "Seeking a Better Understanding of Cyber Infidelity: applying Sternberg's Triangular Theory of Love to an atheoretical field" (2014). Theses and Dissertations. 126.

https://ir.library.illinoisstate.edu/etd/126

This Thesis is brought to you for free and open access by ISU ReD: Research and eData. It has been accepted for inclusion in Theses and Dissertations by an authorized administrator of ISU ReD: Research and eData. For more information, please contact ISUReD@ilstu.edu. 


\title{
SEEKING A BETTER UNDERSTANDING OF CYBER INFIDELITY: APPLYING STERNBERG'S TRIANGULAR THEORY OF LOVE TO AN ATHEORETICAL
}

\section{FIELD}

\author{
Lauren E. Hardy
}

33 Pages

May 2014

The recent phenomenon of cyber infidelity is greatly increasing due to the availability and technology. But, current research is atheoretical, lacking a common language as to how cyber infidelity affects the face-to-face couple. Applying Sternberg's Triangular Theory of Love (1986) is a step in defining aspects of the effects of cyber infidelity. Language among existing research is strikingly comparable to Sternberg's theory. Applying this theory and making the applications using Sternberg's components shows that this theory has the strong potential to create a common language concerning the effects cyber infidelity has on the face-to-face couple. 
SEEKING A BETTER UNDERSTANDING OF CYBER INFIDELITY: APPLYING

\section{STERNBERG'S TRIANGULAR THEORY OF LOVE \\ TO AN ATHEORETICAL}

FIELD

LAUREN E. HARDY

A Thesis Submitted in Partial

Fulfillment of the Requirements

for the Degree of

MASTER OF SCIENCE

Department of Family and Consumer Sciences

ILLINOIS STATE UNIVERSITY

2014 
Copyright 2014 Lauren E. Hardy 
SEEKING A BETTER UNDERSTANDING OF CYBER INFIDELITY: APPLYING STERNBERG'S TRIANGULAR THEORY OF LOVE

TO AN ATHEORETICAL

FIELD

LAUREN E. HARDY

COMMITTEE MEMBERS:

Bill Anderson, Chair

Connor Walters

Jennifer Banning 


\section{ACKNOWLEDGEMENTS}

I would like to thank my committee, Dr. Bill Anderson, Dr. Connor Walters, and Dr. Jennifer Banning, who were more than generous with their time and guidance. I would like to give a special thank you to my thesis chair, Dr. Anderson, for always having my best interest at heart and his continuous support throughout my undergraduate and graduate career. My committee helped me feel prepared to take on the next chapter of my life; giving me confidence and leadership direction and for that I am so grateful. I would also like to thank Ryan Knox and Josh Kauten for their mentorship, support, and endless supply of post-it notes. Lastly, I would like to thank the other graduate students from HDFR and Child Life. Having them throughout this experience not only helped me get through but provided me with friendships and memories I will always cherish.

This thesis is dedicated to my parents, Gilbert and Janet Hardy, without their guidance and support my college career would not have been possible. They have been with me every step of the way with their constant love and support. I thank you both for being my strength throughout my academic career, I love you.

L.E.H. 


\section{CONTENTS}

\section{CHAPTER}

I. SEEKING A BETTER UNDERSTANDING OF CYBER INFIDELITY: APPLYING STERNBERG'S TRIANGULAR THEORY OF LOVE TO AN ATHEORETICAL FIELD

Abstract

Cyber Infidelity

Cyber Infidelity: An atheoretical field

Sternberg's Triangular Theory of Love

Intimacy

Passion

Decision/Commitment

Sternberg's Role in Relationships

Sternberg's Intimacy in Cyber Infidelity Literature

Sternberg's Passion in Cyber Infidelity Literature

Sternberg's Decision/Commitment in Cyber Infidelity Literature

Conclusion

Expansion of Current Research 
II. REVIEW OF RELATED LITERATURE 17

Introduction to Cyber Infidelity 17

Existing Research 17

Sternberg's Triangular Theory of Love 22

Intimacy $\quad 23$

Passion $\quad 24$

Decision/Commitment 24

Types of Love 25

Development of Sternberg's Triangular Theory 26

$\begin{array}{ll}\text { Conclusion } & 28\end{array}$

$\begin{array}{ll}\text { REFERENCES } & 30\end{array}$

APPENDIX A: $\quad$ Image of Sternberg's Triangular Theory of Love 32

APPENDIX B: $\quad$ Image of Sternberg's Triangular Theory Types of Love 33 


\title{
CHAPTER I
}

\section{SEEKING A BETTER UNDERSTANDING OF CYBER INFIDELITY: APPLYING STERNBERG'S TRIANGULAR THEORY OF LOVE TO AN ATHEORETICAL}

FIELD

\begin{abstract}
The recent phenomenon of cyber infidelity is vastly increasing due to the availability of technology. But, current research is atheoretical, lacking a common language as to how cyber infidelity affects the face-to-face couple. Applying Sternberg's Triangular Theory of Love (1986) is a positive step in defining aspects of the effects of cyber infidelity. Language among existing research is strikingly comparable to Sternberg's theory. Applying this theory and making the applications using Sternberg's components shows that this theory has the strong potential to create a common language concerning the effects cyber infidelity has on the face-to-face couple.

\section{Cyber Infidelity}

The popularity and technological advancement of developing relationships online, i.e., Second Life, World of Warcraft, Ashley Madison site, have resulted in a new category of infidelity: cyber infidelity. Such "internet infidelity is different from other known, or traditional, infidelities in that it appears to be anonymous and relatively safe,
\end{abstract}


as it can be pursued in the privacy of one's own home or office" (Atwood, 2005, p. 118). Throughout this paper, cyber infidelity will be defined as an internet relationship with another individual (actual, not virtual) that is maintained electronically, involves elements of intimacy, passion, and commitment, and conflicts with an established, ongoing, faceto-face relationship.

The quick rise of this phenomenon has left current literature on cyber infidelity to be admittedly lacking, focusing noticeably more on intervention and therapeutic techniques rather than the actual effects of the infidelity on the face- to-face couple (Atwood, 2005; Hertlein \& Piercy, 2006; Whitty, 2003; Whitty \& Carr, 2005). This lack of literature is perhaps derived from varying perceptions and definitions of cyber infidelity, which certainly have the ability to create difficulties for therapists in treating this infidelity (Atwood, 2005; Whitty, 2003). Where the couple is concerned, "Infidelity depends a great deal on the couple's understanding of the contract they have with one another and additionally when they define that contract as being threatened" (Atwood, 2005 , p. 118). This is going to vary from couple to couple; they are going to place different emphasis on certain aspects of their relationship, and each couple will have different viewpoints on what actions are considered infidelity in the context of their relationship (Hertlein \& Piercy, 2006). Not only is there no agreed upon definition among researchers and therapists, this same lack of a clear description may also create difficulty for the couple as they are presented with different viewpoints by different practitioners.

Schneider (2003) states that cyber infidelity has considerable impact on relationships, including feelings of betrayal, decreased desire for relational sex with one's 
partner, and the betrayed partner making critical self-comparisons with the fantasy online partner. Self-comparisons, in this situation, have the ability to lead to a negative perception not just in one's self but also can lead to a negative perception of the current relationship and the future for the relationship. From this, further inference that cyber infidelity causes considerable shifts in the face-to-face couple's relationship. Understanding these shifts will allow researchers and practitioners to better understand the effects of cyber infidelity as well the repercussions of the cyber infidelity interactions (Whitty, 2003).

Millner (2008) conducted a case study focusing on intimacy with detachment. The case study focused on a 43 year old male. The subject "expressed surprise that he could communicate effectively with his online companion" stating that he felt a new energy because of this online relationship (Millner, 2008, p. 80). The subject sought counseling because he was considering leaving his wife due to his online relationship with a woman whom he had never met face-to-face. He reported that, "he made plans to be with his family on weekends, but often stole time away to get to the internet" (Millner, 2008, p. 80). Millner (2008) reported that the results of the case study show the subject admitting he loved his wife and children even though he "engaged in a very intense online affair that consumed a great deal of his energy and time" (p. 80). The discussion of this case study reported that the subject had an "inability to establish intimate communication with his spouse was reinforced by his intimate disclosures to a virtual stranger." This study indicates that cyber infidelity has the potential to take away 
components, such as intimacy, away from the face-to-face relationship due to that component being used between the online couple.

Other than perceptions likely varying from couple to couple, perceptions are also apparently varied between male and female. Hackathorn \& Harvey (2011) conducted a study to predict sexual double standards that occur in reactions to computer-mediated infidelity. A total of 115 undergraduate psychology students, 53 males and 62 females, participated. The average age was 19.97 and the majority of participants were Caucasian and heterosexual. Results showed that males are more forgiving when other males commit cyber infidelity, and vice-versa; females are more forgiving toward females committing cyber infidelity. Results also indicated that both genders are more likely to view the opposite sex committing cyber infidelity as more threatening or upsetting.

"The research, to date, suggests that cyber-affairs can have a real and possibly serious impact on the offline relationship" (Whitty \& Carr, 2005, p. 104). However, with the varying perceptions of cyber infidelity, and although it may not be perceived as infidelity in the same way by all individuals, it has a potential negative effect on couples, but what those effects might include, or the specific degree of those effects, remains unclear. To date, research has only suggested the influence that cyber infidelity has on the face-to-face couple; this impact still needs to be studied.

\section{Cyber Infidelity: An atheoretical field}

Current research on cyber infidelity is essentially atheoretical and lacking a common language and understanding. Application of theory(s) to this phenomenon could 
advance the understanding as well as address some of the misunderstandings surrounding cyber infidelity. The act of cyber infidelity has the potential to impact the face-to-face relationship in that it can take time and attention away from the relationship. It initially appears that Sternberg's (1986) Triangular Theory of Love could be applied to cyberinfidelity, expanding existing understandings and explanations. Sternberg focuses on three relational elements: intimacy, passion, and decision/commitment. The triangular theory also utilizes eight different types of love that involve variations of the three components and their strength at a given time. Sternberg's theory is used to understand the shifts in the face to face relationship. Knowing, understanding, and perhaps anticipating these shifts could help researchers pinpoint what element of cyber infidelity is currently impacting in the face to face relationship. Given that existing research suggests that cyber infidelity will indeed influence the face to face relationship (Atwood, 2005; Whitty \& Carr, 2005; Millner, 2008; Schneider, 2003), knowing exactly how and what aspects (e.g. Sternberg) suffer the most due to the online infidelity could help move research forward.

For example, current literature is already using the terms intimacy, passion, and commitment regarding cyber infidelity. However, the terms don't necessarily have the same meaning throughout the literature. Milner (2007) speaks largely on intimacy; stating, "Intimacy with detachment is exactly what one can accomplish by connecting with and internet partner" (p.79). This statement refers to intimacy as being a form of an emotional bond without any commitment to their online partner. Atwood (2005) also uses the term intimacy, stating, "Infidelity that consists of taking energy of any sort (thoughts, feelings, and behaviors) outside of the committed relationship in such a way 
that it damages interactions between the couple and negatively impacts the intimacy in the relationship" (p. 118). Atwood is making the statement that by forming an emotional bond with an online partner; it will directly negatively impact the face-to-face relationship. Therefore, it seems that Atwood (2005) and Milner (2007) do not share a common definition of intimacy as it is applied to cyber infidelity. These examples further display evidence that literature is lacking common definitions of relationship effects due to cyber infidelity.

\section{Sternberg's Triangular Theory of Love}

The Triangular Theory of Love was introduced by Robert Sternberg in 1986. According to Sternberg, love in a close relationship can be understood in terms of three components that together can be viewed as forming the vertices of a triangle (Sternberg, 1986). The three components involved are intimacy (the top vertex of the triangle), passion (the left-hand vertex of the triangle), and decision/commitment (the right-hand vertex of the triangle). Sternberg $(1986,1997,2006)$ reported that together these three components can explain love in a given close relationship. The type of love each partner experiences in the close relationship depends on the strength presented of each

component. When all three components are present at the same time consummate love exists; however, according to Sternberg, this hardly ever happens consistently. Also, each member of a couple usually emphasizes one or more of the elements while the other member of the couple may emphasize a slightly different combination or place more emphasis on one element compared to their partner. 


\section{Intimacy}

The top vertex of Sternberg's triangle is intimacy described as sharing emotions and stories with other. Intimacy is enhanced by self-disclosure (Harvey \& Weber, 2002) and believed to allow each partner to experience warmth within the loving relationship. Sternberg and Grajek (1984) identified 10 clusters in intimacy: 1) desire to promote the welfare of the loved one; 2) experienced happiness with the loved one; 3 ) high regard for the loved one; 4) being able to count on the loved one in times of need; 5) mutual understanding with the loved one; 6) sharing of one's self and one's possessions with the loved one; 7) receipt of emotional support from the loved one; 8) giving of emotional support to the loved one; 9) intimate communication with the loved one; and 10) valuing of the loved one in one's life. This closeness can be looked at as an emotional investment between both partners.

\section{Passion}

The left hand vertex of Sternberg's triangle is labeled passion, involving an “erotic interest in another" (Harvey \& Weber, 2002, p. 85) and considered to be an intense longing for union with the other. Sternberg (1992) describes passion as the "drives that lead to romance, physical attraction, sexual consummation, and related phenomena in loving relationships" (p. 315). The passion component within relationships can also refer to the amount of motivation provided by each partner towards maintaining the relationship. The desires each partner has acts as their drives and efforts within the relationship. 


\section{Decision/Commitment}

Decision/commitment completes the triangle. This component involves making a decision to stay with the other and to defer this type of relationship with others (Harvey \& Weber, 2002). Sternberg (1997) states, "Decision/commitment refers, in the shortterm, to the decision that one loves a certain other, and in the long-term, to one's commitment to maintain that love" (p. 315). However, the decision and commitment do not necessarily have to go together, in that one can decide to love someone without being committed to the love in the long-term, or one can be committed to a relationship without acknowledging that one loves the other person in the relationship (Sternberg, 1997). Commitment is a purely cognitive event. When a partner loves someone without being committed to the relationship long-term they have cognitively made that decision that they don’t necessarily want a long-term relationship.

\section{Sternberg's Role in Relationships}

Sternberg's (1986) work has played a long-standing and successful role in researching relationships. It can be suggested that using Sternberg's definitions for intimacy, passion, and commitment would help create a common language among cyber infidelity. Lusterman (1988) describes that a certain level of emotional intimacy is reserved for the couple, not to be shared with others. Perhaps it is this that is lessened in cyber-infidelity. If so, perhaps research is already using and/or describing concepts of eth triangular theory to describe the effects of the relationship due to online intimacy.

\section{Sternberg's Intimacy in Cyber Infidelity Literature}

The result of intimacy in a relationship will be feelings of connectedness and closeness (Sternberg, 1986). Current literature contains aspects of this definition and if 
there was a common, shared, terminology, results could be better understood. The following quotes indicate usages of intimacy which could be better compared and contrasted using Sternberg's concept of intimacy.

For instance, the statement, "I was able to get emotional fulfillment from the people that I met online" (Millner, 2007, p. 79), could be perceived as Sternberg's concept of intimacy. This fulfillment could be perceived as the sharing of emotions and stories with another, as previously mentioned. When Atwood (2005) describes individuals who "interact over the internet, where the conversation generally offers unconditional support and comfort" (p. 119), she could be describing an intimacy that is enhanced by selfdisclosure (Sternberg, 1986, 1998). Such self-disclosure can result in feelings of connectedness and being bonded in loving relationships and will likely come to be understood as, and experienced as, warmth. Other examples of intimacy include:

- "Internet infidelity is based primarily on the extent of the interaction and the emotional commitment of the surfer gives to the internet" (Atwood, 2005, p. 119).

- "The assumption that anything that is deliberately hidden from a partner can create an emotional distance that could present a serious problem in the relationship" (Atwood, 2005, p. 118).

- "I was drawn to the intimacy that these men were expressing that my (then) husband wouldn't/couldn't' (Millner, 2007, p. 79).

- 'Experiencing a strong emotional connection with one's partner and not having that connection in one's primary relationship might contribute to limited 
discussions about problems in the primary relationship" (Hertlein \& Piercy, 2006, p. 368).

"Increased computer usage may diminish shared time between couples" (Hertlein \& Piercy, 2006, p. 368). "Internet infidelity can be a result of the couple's inability to communicate feelings or needs to one another" (Atwood, 2005, p. 124). As such, intimacy can still be cast as "an emotional investment in the relationship, it can be seen as a slowly developing foundation of love that can be very difficult to achieve" (Anderson, In Press).

\section{Sternberg's Passion in Cyber Infidelity Literature}

Sternberg (1986) views passion as referring to the yearning of romance, physical attraction, and sexual consummation. The following are examples that if understood as Sternberg's passion could help create a common language among the act of cyber infidelity. For example, Atwood (2005) writes, "This electronic bond can offer the fantasy of the excitement, romance, and passion that may be missing in the current relationship" (p. 119). This is readily compared to Sternberg's $(1986,1998)$ concept of passion as involving an erotic interest in another and being largely the expression of desires and needs. Other examples include:

- "Most participants feel sexual in a medium that makes it relatively easy to flirt or share sexual fantasies online" (Hertlein \& Piercy, 2006, p. 367). 
- Two thirds of couples that completed a study where they experienced cyber infidelity in their face-to-face relationship reported that they lost interest in sex with their spouse (Hertlein \& Piercy, 2006).

- The anonymity allows the surfer to secretly engage in erotic chats with little or no fear of being caught by his or her spouse (Atwood, 2005, p. 120).

\section{Sternberg's Decision/Commitment in Cyber Infidelity Literature}

Examples of language within current literature that could be explained or expanded with Sternberg's decision/commitment are those that involve making a decision to stay with the specific other and to defer this type of relationship with others (Harvey \& Weber, 2002). Because more time in online relations can conceivably "diminish shared time between couples" (Hertlein \& Piercy, 2006, p. 368), the decision to spend time online could weaken face-to-face commitment. Examples of Sternberg's decision/commitment in existing studied include:

- "This type of interaction can become a problem for the couple when the surfer goes on to the internet to chat with cyber friends instead of spending time with his or her spouse" (Atwood, 2005, p. 120).

- One significant element of the mutual trust in a marriage is the unspoken vow that the couple will remain sexually exclusive (Lusterman, 1998). 
These appear best connected to the decision element, the short-term decision that one loves a certain other. Perhaps the short term decision can be made in the cyber direction as well.

Miller (2007), reported, "Frank reported that he spent extended periods of time both at work and at home having cybersex with his online companion" (p. 80). These "extended times" could be descriptive of Sternberg's (1997) commitment component, described as "the decision that one loves a certain other, and in the long-term, to one's commitment to maintain that love" (p. 315). Certainly, infidelity "depends a great deal on the couple's understanding of the contract they have with one another and additionally when they define that contract as being threatened" (Atwood, 2005, p. 118). But, as with intimacy and passion, Sternberg's (1998) commitment seems to readily apply here.

It can be quite complicated to manage the intimacy component of love and extraordinarily difficult to control passion. But, one has substantial control over the decision/commitment component, and this control may either further or prevent the growth of the relationship into a qualified romantic relationship. Decision and commitment are then derived largely from a common, cognitive scheme and dedication to a relationship, though the two are not necessarily simultaneous (Anderson, In Press).

Noticing the examples in current literature that use intimacy, passion, and commitment in similar definitions that Sternberg uses when describing loving relationships, it seems as though applying the Triangular Theory of Love to cyber infidelity can indeed create the common language current literature is missing, or 
overlooked. Literature continues to state that cyber infidelity is affecting not just the face-to-face relationship but the family as a whole; "Many spouses report that the surfer spouse has withdrawn his sexuality, intimacy, and attention from the family" (Atwood, 2005, p. 126). These three components cover each factor of a relationship and cyber infidelity seems to be affecting all three. From current literature, it seems as though the intimacy component tends to be affected the most. Because of the anonymity factor, it may be that users feel more comfortable sharing emotions and personal stories with others over the internet.

\section{Conclusion}

The atheoretical aspect of cyber infidelity has resulted in a lack of definition in current research. Existing literature also lacks a connection and a clear understanding of the effects of cyber infidelity. Applying Sternberg's Triangular Theory can serve to explain this phenomenon and unify this field of research. Applying Sternberg's theory shows the relationship current explanations and definitions have to Sternberg's three components; applying this theory in the future can create common language and unite literature moving forward.

Within the reviewed literature, it appears that that intimacy is the most affected component in the face-to-face relationships due to cyber infidelity. This seems to be true due to the anonymous factor of communicating with someone via the internet. Being able to type your thoughts and emotions tends to be much easier for individuals in today's technological savvy society. Another reason why intimacy is shown to be the most affected component is because it tends to be the component individuals desire the 
most, but the hardest to keep constant. That is, with the factors of work and children it can be difficult for couples to keep the emotional bond constant. When this bond starts to diminish, a partner may then turn to the internet to fill this need in their relationship.

\section{Expansion of Current Research}

The future for this current research topic involves directly examining the Ashley Madison site; an online site that promotes cyber affairs. Ashley Madison's website catch phrase is, "Life is short. Have an affair," and claims that is has over 25,490,000 anonymous members. Members are individuals that are currently married or in a relationship who are looking to have an affair started online. The expansion of research will apply Sternberg's Triangular Theory of Love (1986), McCubbin and Patterson's double ABC-X model (1982, 1983), and the revisions of Sternberg's love scale (1997).

Sternberg's love scale (1997) involves 12 statements for each component; intimacy, passion, and commitment. Permission to revise this love scale has been secured for the expansion of this research study. Research will focus on asking members to respond to statements in order to see which Sternberg component is being the most affected; i.e. intimacy, passion, or commitment.

Combining Sternberg's Theory of Love with McCubbin and Patterson's double ABC-X model (1982, 1983); research will be able to indicate stressors, resources, and perceptions that may vary due to cyber infidelity. Research will also aim to explain the shifts in the face-to-face relationship with the revision of Sternberg's love scale. Applying the double ABC-X model will indicate how the shifts affect the face-to-face couple's stressors, resources, and perceptions of the cyber infidelity. 


\section{Future Research}

Suggestions for future research primarily include using Sternberg's intimacy, passion, and commitment components and move into further, into Sternberg's types of love. Sternberg (1988) generates eight different types of love. Each of the types of love will consist of a different combination of the three components; intimacy, passion and commitment. These different combinations will have varying degrees of each

component. The eight types of love are as follows (Sternberg \& Barnes, 1988; Sternberg, 1997):

- Non-love refers simply to the absence of all three components of love.

- Liking results when one experiences only the intimacy component of love in the absence of the passion and decision/commitment components.

- Infatuated love results from the experiencing of the passion component in the absence of the other components of love.

- Empty love arises from the decision that one loves another and is committed to that love in the absence of both the intimacy and passion components of love.

- Romantic love derives from a combination of the intimacy and passion components.

- Companionate love derives from a combination of the intimacy and decision/commitment components of love.

- Fatuous love results from the combination of the passion and decision/commitment components in the absence of the intimacy component. 
- Consummate, or complete love, results from the full combination of all three components.

In most instances, a relationship will involve all three components but in fluctuating amounts.

Applying Sternberg's types of love will allow researchers to see the shifts over time in the relationship due to cyber infidelity. This application has the capacity to show how couples move from one type of love to another due to cyber infidelity. For example, Hertlein \& Piercy (2006) state, "The level of secrecy charged with sexual excitement can also affect the ability to build trust between the individuals in the relationship" (p. 367). Applying this statement to the Triangular Theory of Love allows us to strongly assume that the two components being spoken on are passion and intimacy. Applying Sternberg's types of love can show the movement from romantic love (passion and intimacy) to empty love (commitment). Furthering these applications will continue to provide a common language as well as offer definitions for the shifts that occur in the face-to-face relationship due to cyber infidelity. 


\section{CHAPTER II}

\section{REVIEW OF RELATED LITERATURE}

\section{Introduction to Cyber Infidelity}

Cyber Infidelity is a relatively new phenomenon for which a common definition had not been developed. Initially the search terms online cheating, virtual cheating, and virtual flirting were used; however, those terms proved insufficient for this study as they were not related to relationships. The word 'cyber' was the next choice. Cyber affairs, cyber cheating, and cyber-sex were used. It quickly became evident that when the word 'cheating' was included in search terms, the results were largely related to academic dishonesty. 'Cyber affairs' resulted in homeland security sites and 'cyber-sex' resulted in school bullying between genders. The search term 'infidelity' was then utilized. Infidelity, defined as unfaithfulness within a relationship, produced the search results needed for this study specifically concerning couple relationships. The term 'cyber' proved most effective being paired with the term 'infidelity' because it produced the most accurate results for this research topic.

\section{Existing Research}

Current literature on cyber infidelity is admittedly lacking, focusing more on intervention and therapeutic techniques rather than the actual effects of the infidelity on the face- to-face couple (Atwood, 2005; Hertlein \& Piercy, 2006; Whitty, 2003; Whitty \& 
Carr, 2005). The lack of existing literature is perhaps derived from varying perceptions and definitions of cyber infidelity, which have the ability to create challenge for therapists in treating this infidelity (Atwood, 2005; Whitty, 2003). "Infidelity depends a great deal on the couple's understanding of the contract they have with one another and additionally when they define that contract as being threatened" (Atwood, 2005, p. 118). This is going to vary from couple to couple; they are going to place different emphasis on certain aspects of their relationship, and each couple will have different viewpoints on what actions are considered infidelity in the context of their relationship (Hertlein \& Piercy, 2006). Not only is there no agreed upon definition among researchers and therapists, this lack of a clear description may also create difficulty for the couple as they are presented with different viewpoints by different practitioners.

Schneider (2003) states that cyber infidelity has considerable impact on relationships, including feelings of betrayal, decreased desire for relational sex with one's partner, and the betrayed partner making critical self-comparisons with the fantasy online partner. Self-comparisons, in this situation, have the ability to lead to a negative perception not just in one's self but also can lead to a negative perception of the current relationship and the future for the relationship. From this, further conclusion can be made that cyber infidelity causes considerable shifts in the face-to-face couple's relationship. Understanding these shifts will allow researchers and practitioners to better understand the effects of cyber infidelity as well the repercussions of the cyber infidelity interactions (Whitty, 2003). 
Other than perceptions varying from couple to couple, perceptions are also apparently varied between male and female. Hackathorn \& Harvey (2011) conducted a study to predict sexual double standards that occur in reactions to computer-mediated infidelity. A total of 115 undergraduate psychology students, 53 males and 62 females, participated in this study. The average age was 19.97 and the majority of participants were Caucasian and heterosexual. The results showed that males are more forgiving when other males commit cyber infidelity, and vice-versa; females are more forgiving toward females committing cyber infidelity. Results also indicated that we are more likely to view the opposite sex committing cyber infidelity as more threatening or upsetting.

Henline, Lamke, \& Howard (2007) also explored perceptions of cyber infidelity, this time from the viewpoint of college students in committed relationships. The sample consisted of 123 college students in committed relationships, 51 men and 72 women. The majority of participants held the understanding with their partner that marriage was in their future plans as a couple. Participants were mainly Caucasian with a mean age of 21.03 years. Results from this study indicated that subjects perceived online infidelity to be a "multifaceted phenomenon that includes both a sexual component (e.g., online sex, flirting, sex chat) and an emotional component (e.g., talking to people online about deeply personal things, saying "I love you" to someone online)" (Henline et al., p. 123). The results of this study allow researchers and practitioners to be aware that for some couples there are clearly both sexual and emotional components involved in cyber 
infidelity. Both of these components have the ability to affect the face-to-face couple; in what way specifically is still unknown.

With the varying perceptions of cyber infidelity it is clear that, although it may not be perceived as infidelity in the same way by all individuals, it potentially has a negative effect on couples and what those affects might include or the degree of those effects remains unclear. "The research, to date, suggests that cyber-affairs can have a real and possibly serious impact on the offline relationship" (Whitty \& Carr, 2005, p. 104). To date, current literature has only suggested this impact that cyber infidelity has on the face-to-face couple; this impact still needs to be studied. It is clear research in cyber infidelity is lacking and needs to grow. Furthermore, current research on cyber infidelity is atheoretical. This causes the research to lack a common language and understanding. Providing application to theory(s) to this phenomenon could advance the understanding as well as the misunderstandings surrounding cyber infidelity.

\section{Sternberg's Triangular Theory of Love}

The Triangular Theory of Love was introduced by Robert Sternberg in 1986. According to the theory, love in a close relationship can be understood in terms of three components that together can be viewed as forming the vertices of a triangle (Sternberg, 1986). The three components involved are intimacy (the top vertex of the triangle), passion (the left-hand vertex of the triangle), and decision/commitment (the right-hand vertex of the triangle). Sternberg $(1986,1997,2006)$ reported that together these three components can explain love in a given close relationship. The type of love each partner experiences in the close relationship depends on the strength presented of each 
component. When all three components are present at the same time consummate love exists; however, according to Sternberg, this hardly ever happens consistently. Also, each member of a couple usually emphasizes one or more of the elements while the other member of the couple may emphasize a slightly different combination or place more emphasis on one element compared to their partner.

The act of cyber infidelity has the potential to impact the face-to-face relationship in that it has the ability to take time and attention away from the relationship. It initially appears that Sternberg's (1986) Triangular Theory of Love could be applied to cyberinfidelity, expanding existing understandings and explanations. Sternberg focuses on three relational elements: intimacy, passion, and decision/commitment. These three components are involved in all couple relationships at varying points. The triangular theory also utilizes eight different types of love that involve variations of the three components and their strength at a given time. Sternberg's theory could conceivably be used to explain the shifts in the face to face relationship (Schneider, 2003; Whitty, 2003). Knowing, understanding, and perhaps anticipating these shifts could help researchers pinpoint what element of cyber infidelity is currently impacting in the face to face relationship. Given that existing research suggests that cyber infidelity will indeed influence the face to face relationship, knowing exactly how and what aspects (e.g. Sternberg) suffer the most due to the online infidelity will help move research forward.

\section{Intimacy}

The top vertex of Sternberg's triangle is intimacy described as sharing emotions and stories with other. Intimacy is enhanced by self-disclosure (Harvey \& Weber, 2002) and believed to allow each partner to experience warmth within the loving relationship. 
Sternberg and Grajek (1984) identified 10 clusters in intimacy: desire to promote the welfare of the loved one; experienced happiness with the loved one; high regard for the loved one; being able to count on the loved one in times of need; mutual understanding with the loved one; sharing of one's self and one's possessions with the loved one; receipt of emotional support from the loved one; giving of emotional support to the loved one; intimate communication with the loved one; and valuing of the loved one in one's life. These 10 clusters can perhaps be used among practitioners to inform them of this component used within theory to examine and explain intimacy within the loving relationship. For instance, intimacy includes sharing emotions with your partner; sharing these feelings will result in feelings of connectedness. This closeness can be looked at as an emotional investment between both partners.

\section{Passion}

The left hand vertex of Sternberg's triangle is labeled passion. "Passion involves erotic interest in another" (Harvey \& Weber, 2002, p. 85) and is considered to be an intense longing for union with the other. According to Sternberg (1992), "Passion refers to the drives that lead to romance, physical attraction, sexual consummation, and related phenomena in loving relationships" (p. 315). The passion component within relationships can also refer to the amount of motivation provided by each partner towards maintaining the relationship. The desires and needs each partner has acts as their drives and efforts within the relationship.

\section{Decision/Commitment}

Decision/commitment makes up the right-hand vertex of the triangle and also completes the triangle described by Sternberg. This component involves making a 
decision to stay with the other and to defer this type of relationship with others (Harvey \& Weber, 2002). Sternberg (1997) states, "Decision/commitment refers, in the shortterm, to the decision that one loves a certain other, and in the long-term, to one's commitment to maintain that love" (p. 315). According to this theory, the decision and commitment component do not necessarily have to go together, in that one can decide to love someone without being committed to the love in the long-term, or one can be committed to a relationship without acknowledging that one loves the other person in the relationship (Sternberg, 1997). Commitment is a purely cognitive event. When a partner loves someone without being committed to the relationship long-term they have cognitively made that decision that they don't necessarily want a long-term relationship.

\section{Types of Love}

These three components can work together or separately but will remain interactive with each other. All three components are important within a relationship; however, their importance may vary or differ from one relationship to another, or across time. Sternberg (1997) stated, "different kinds of love can be generated by limiting cases of different combinations of the components" (p. 316).

With the three components of love described above, Sternberg generates eight different types of love. Each of the types of love will consist of a different combination of the three components; intimacy, passion and commitment. These different combinations will have varying degrees of each component. The eight types of love are as follows (Sternberg \& Barnes, 1988; Sternberg, 1997): Non-love refers simply to the absence of all three components of love. Liking results when one experiences only the intimacy component of love in the absence of the passion and decision/commitment 
components. Infatuated love results from the experiencing of the passion component in the absence of the other components of love. Empty love arises from the decision that one loves another and is committed to that love in the absence of both the intimacy and passion components of love. Romantic love derives from a combination of the intimacy and passion components. Companionate love derives from a combination of the intimacy and decision/commitment components of love. Fatuous love results from the combination of the passion and decision/commitment components in the absence of the intimacy component. Consummate, or complete love, results from the full combination of all three components. In many instances of a relationship will involve all three components but in fluctuating amounts.

\section{Development of Sternberg's Triangular Theory}

Love has long been viewed as something that would be inconsistent with measurement. When Sternberg's Triangular Theory of Love was first introduced in 1986 many components of the theory were neither reliably tested nor measured. For this reason, in 1987 Sternberg created a 36 item love scale to measure the Triangular Theory of Love. It was concluded that this version had a high internal consistency indicative of convergent and concurrent validity. Evidence of this scale also found high subscale interrelatedness" (Chojnacki \& Brucewalsh, 1990) p. 219). Due to the high subscale interrelatedness, Sternberg was then prompted to revise his original scale; the revised version contains 45 rationally constructed items, 15 items to measure each of the three components (Chojnacki \& Brucewalsh, 1990).

In 1990, Sternberg's Triangular Theory of Love was used in a consumer-object relations study (Shimp \& Madden, 1988). These researchers proposed that consumers 
form relations with consumption objects. These objects can be products, brands, or stores. Shimp and Madden argued that the relationship formed between a consumer and a product can form feelings that "range from antipathy, to slight fondness, all the way up to what would, in person-person relations, amount to love" (p.163). They proposed a framework by adapting Sternberg's Triangular Theory of Love to link analogies between Sternberg's person-person relations and consumer-object relations. A sample size of 90 students from introductory courses in psychology and who were currently involved in dating relationships completed this study. The goal was to assess the reliability and concurrent validity of the Sternberg Triangular Love Scale. The researchers used the three components as well as the eight types of love to view the interactions in the various combinations to determine the nature of consumer's relations with consumption objects. Results supported the validity of the Sternberg scales. Shimp and Madden related Sternberg's eight types of love concept to a special type of attitude with consumers, noting, "just as love itself represents a special type of attitude, consumer-object relationships also are attitudes varying in their direction of intensity" (p.165). For example, the authors compared Sternberg's consummate love to loyalty for consumerobject love. Consummate love involves all three of Sternberg's components; intimacy, passion, and commitment; while loyalty has liking, yearning, and commitment. The illustration of loyalty, or consummate love, in this study in American culture is in the area of sports. Consumers are in love with their favorite sports team, and all three components; liking (intimacy), yearning (passion), and commitment are all extremely strong; "in fact every bit as strong as what is observed between people who are in love" (p.166). 
More recently, Sternberg (1997) presented a construct validation of a love scale based upon the Triangular Theory of Love. With this study, Sternberg was able to look at the theory through action stating, "It is important to consider the triangle of love as it is expressed through action, because action has so many effects on a relationship" (Sternberg, 1997, p. 317). In this study the focus was on internal validation as well as external validation and to test if these components were consistent with the theory, such as determining how well Sternberg's love scale applies to loving relationships of different kinds with different people. Sternberg (1997) concluded that, "the study of love is on its way toward becoming an empirical but theoretically-based discipline” (p. 334). Future research suggestions in this article included conducting direct comparative tests between theories that will allow future theorists to draw upon the best features of existing ones.

\section{Conclusion}

Research is lacking concerning the phenomenon of cyber infidelity. While the popularity and use of technology is rising at such a fast pace, research is lagging. Research on intervention and therapeutic techniques are important when confronting cyber infidelity, but it is also important to know and understand the effects of cyber infidelity in theoretical context. Because research on cyber infidelity is currently atheoretical, applying theory could help move research forward, create a common language, and clear up misunderstandings surrounding this phenomenon. Sternberg's (1997) Triangular Theory of Love has been used over the years to describe the components involved in loving relationships and may prove applicable to cyber relationships. 
The resulting scale has been revised and used in multiple studies to connect emotional feelings. The action of intimacy, passion and commitment has been examined and proven to be an important factor when specifically looking at loving relationships. Applying the Triangular Theory of Love to cyber infidelity could create common language among this phenomenon. Along with creating the much needed common language, Sternberg's theory could help explain the shifts in the face-to-face relationship due to the cyber infidelity; this explanation could then help practitioners know what part of the relationship is being most affected due to this new form of infidelity. 


\section{REFERENCES}

Anderson, J.W. (In press, 2015). Sternberg's triangular theory of love. In C.L. Shehan (Ed.), The Encyclopedia of Family Sciences. Hoboken, NJ: Wiley-Blackwell.

Atwood, J. D. (2005). Cyber-affairs: "What's the big deal?" Therapeutic considerations. Journal of Couple \& Relationship Therapy, 4(2/3), 117-134.

Chojnacki, J. T., \& Walsh, W. B. (1990). Reliability and concurrent validity of the Sternberg Triangular Love Scale. Psychological Reports, 67(1), 219-224.

Hackathorn, J., \& Harvey, R. (2011). Sexual double standards: Bias in perceptions of cyber- infidelity. Sexuality \& Culture, 15(1), 100-113.

Harvey, J. H., \& Weber, A. L. (2001). Odyssey of the heart: Close relationships in the 21st century. Mahwah, NJ: Psychology Press.

Henline, B. H., Lamke, L. K., \& Howard, M. D. (2007). Exploring perceptions of online infidelity. Personal Relationships, 14(1), 113-128.

Hertlein, K. M., \& Piercy, F. P. (2006). Internet infidelity: A critical review of the literature. Family Journal, 14(4), 366-xxx.

Lusternman, D. (1988). Infidelity: A survival guide. New York: MJF Books.

McCubbin, H. and Patterson, J. (1982). Family adaptation to crisis. Family Stress, Coping and Social Support, McCubbin, H., Cauble, A. and Patterson, J. (Eds), pp. 5-25. Springfield, IL: C.C. Thomas

McCubbin, H. I. \& Patterson, J.M. (1983a) 'The Family Stress Process: The Double ABCX model of adjustment and adaptation', in H. I . McCubbin, M. B. Sussman \& J.M. Patterson (eds) Social Stress and the Family

Millner, V. S. (2008). Internet infidelity: A case of intimacy with detachment. The Family Journal, 16(1), 78-82.

Schneider, J. P. (2003). Effects of cybersex addiction on the family: Results of a survey. Sexual Addiction \& Compulsivity: The Journal of Treatment and Prevention, 7(12), 31-58. 
Shimp, T. A., \& Madden, T. J. (1988). Consumer-object relations: A conceptual framework based analogously on Sternberg's triangular theory of love. Advances in Consumer Research, 15(1), 163-168.

Sternberg, R.. J. (1986). A triangular theory of love. Psychological Review, 93, 119-135.

Sternberg, R. J. (1997). Construct validation of a triangular love scale. European Journal of Social Psychology, 27(3), 313-335.

Sternberg, R. J., \& Barnes, M. L. (1988). The psychology of love. Robert J. Sternberg, Michael L. Barnes [editors]. New Haven: Yale University Press, c1988.

Sternberg, R. J., \& Grajek, S. (1984). The nature of love. Journal of Personality and Social Psychology, 47(2), 312.

Sternberg, R. J. (1997). Construct validation of a triangular love scale. European Journal of Social Psychology, 27(3), 313-335.

Sternberg, Robert. J. 2006. "A duplex theory of love." In The New Psychology of Love, edited by Robert J. Sternberg, and Karen Weis, 184-199. New Haven: Yale University Press.

Whitty, M. T. (2003). Pushing the wrong buttons: Men's and women's attitudes toward online and offline infidelity. CyberPsychology \& Behavior, 6(6), 569-579.

Whitty, M. T., \& Carr, A. N. (2005). Taking the good with the bad: Applying Klein's work to further our understandings of cyber-cheating. Journal of Couple \& Relationship Therapy, 4(2/3), 103-115. doi:10.1300/J398v04n0210 
APPENDIX A

IMAGE OF STERNBERG'S TRIANGULAR THEORY OF LOVE

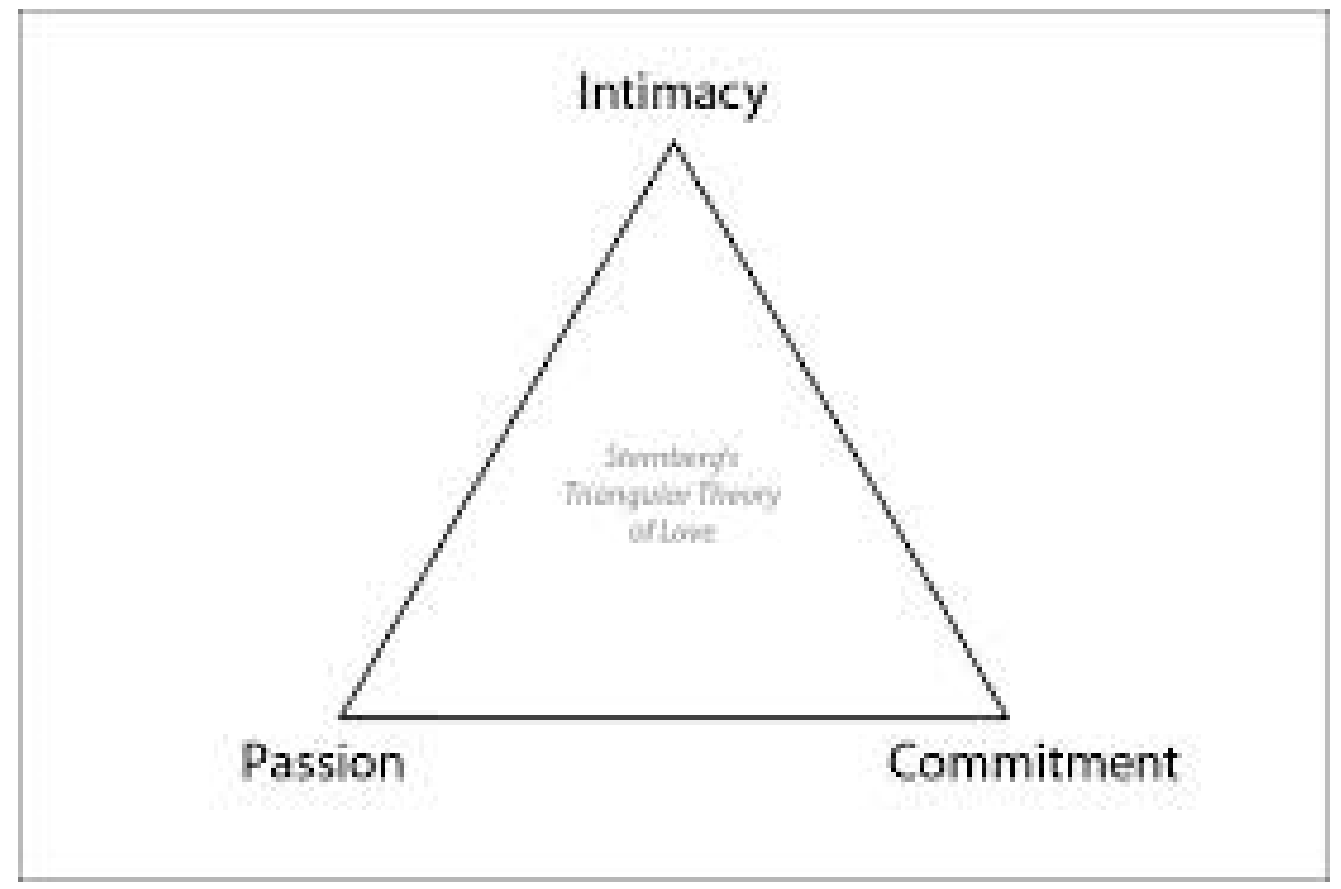


APPENDIX B

IMAGE OF STERNBERG'S TRIANGULAR THEORY TYPES OF LOVE

Intimacy Passion Commitment

\begin{tabular}{lccc}
\hline Nonlove & - & - & - \\
Liking & + & - & - \\
Infatuated Love & - & + & - \\
Empty Love & - & - & + \\
Romantic Love & + & + & - \\
Companionate Love & + & - & + \\
Fatuous Love & - & + & + \\
Consumate Love & + & + & + \\
\hline
\end{tabular}

